\title{
Contributions on the Distribution and Ecology of Vormela peregusna in Turkey
}

\author{
Gökhan YÜRÜMEZ1, Servet ULUTÜRK ${ }^{*}$
}

${ }^{1}$ Batman Üniversitesi Fen-Edebiyat Fakültesi Biyoloji Bölümü, 72060 Batman ORCID ID: Gökhan YÜRÜMEZ: https://orcid.org/0000-0001-5415-2278; Servet ULUTÜRK: https://orcid.org/0000-0001-6812-7583

\begin{abstract}
\begin{tabular}{llll}
\hline Received: 07.03.2019 Accepted: 14.06.2019 & Published online: 30.06.2019 & Issue published: 30.06 .2019
\end{tabular}
Abstract: Although Vormela peregusna (Güldenstädt, 1770) is located under the category of vulnerable (VU) according to the International Union for Conservation of Nature and Natural Resources (IUCN), it has a widespread distribution in our country. The specimens distributed in Batman province were investigated morphologically by the studies conducted between the years of 2016 and 2018. By the presence of a black band at the tip of its tails, these specimens showed similarities with $V$. p. syriaca subspecies. In addition, this study contributes to the distribution boundaries of the species in our country.

Keywords: Vormela peregusna, morphology, IUCN, Batman

\section{Vormela peregusna'nın Türkiye'deki Dağılışı ve Ekolojileri Üzerine Katkılar}

Öz: Vormela peregusna (Güldenstädt, 1770) Doğa ve Doğal Kaynakların Korunması için Uluslararası Birliğe (IUCN) göre duyarlı (VU) kategorisinde yer alan bir tür olmasına rağmen, ülkemizde geniş bir yayılış göstermektedir. 2016-2018 yılları arasında yapılan arazi çalışmaları ile Batman yöresinde tespit edilen V. peregusna örnekleri morfolojik olarak incelenmiştir. Kuyruklarının uç kısmında siyah bir bant bulundurması örneklerimizin $V$. p. syriaca alttürü ile benzerlik gösterdiğini ortaya koymaktadır. Aynı zamanda, bu çalışma ile türün dağılış sınırlarına da katkılar sunulmuştur.
\end{abstract}

Anahtar kelimeler: Vormela peregusna, morfoloji, IUCN, Batman

Omurgalıların en gelişmiş sınıfı olan memeliler dünya üzerinde 27 takıma ait 6213 tür ile temsil edilirken, ülkemizde ise yaklaşık 170 memeli türü dağılış göstermektedir (Wilson \& Reeder, 2005; Eken, Bozdoğan, İsfendiyaroğlu, Kılıç, \& Lise, 2006; Yiğit, Çolak, Sözen, \& Karataş, 2006). Ancak, insanoğlu artan enerji ve besin ihtiyaçları doğrultusunda kaynakları bilinçsizce kullanarak pek çok doğal alanın yok edilmesine neden olmaktadır (Lefeuvre, Laffaille, Feunteun, Bouchard, \& Radureu, 2003; Desrocher, Keagy, \& Cristol, 2008; Chen, Shi, Sivakumar, \& Peart 2016). Palearktik bölgede yedi familya ile temsil edilen Carnivora takımının ülkemizde beş familyası (Canidae, Mustelidae, Ursidae, Felidae ve Hyaenidae) ve bunlara ait 18 tür kaydı bulunmaktadır (Kumerloeve, 1967; Albayrak, Pamukoğlu \& Aşan, 1997). Ülkemizde bugüne kadar büyük yabani memelilerin tespitine yönelik yapılan çalışmalar küçük lokal düzeylerde veya iller bazında yapılırken (Can \& Togan, 2009; Hizal, 2008; Çam \& Ölmez, 2015; Toyran, 2016; Yürümez \& Ulutürk, 2016; Ulutürk \& Yürümez, 2017), baz1 çalışmalarda bölgesel (Özkurt, Sözen, Yiğit, \& Çolak, 1999; İbiş, Tez, Özcan, Yorulmaz, Kaya, \& Mohammad, 2015a; İbiş, Aksöyek, Özcan, \& Tez, 2015b) düzeyde gerçekleşmiştir. İlk kez Rusya'nın Rostov bölgesinden tanımlanan Vormela peregusna (Güldenstädt, 1770), Güneydoğu Avrupa'dan Batı Çin'e kadar, Türkiye, Suriye, Lübnan, Filistin, Israil, Ürdün ve Suudi Arabistan'da yayılış gösterir (Ognev, 1931; Novikov, 1962; Corbet, 1978; Kock, 1983; Harrison \& Bates, 1991; Rıfai, Al-Shafee, AlMelhim, \& Amr, 1999). Palearktik bölge hayvanı olan $V$. peregusna türünün dünyada altı alt türü (V. p. peregusna, $V$. p. syriaca, V.p. alpherakyi, V.p. euxina, V.p. negans ve V.p. pallidor) bulunmaktadır (Gorsuch \& Larivière, 2005). Ülkemizde bugüne kadar $V$. peregusna'ya ait birçok morfolojik ve karyolojik çalışma yapılmıştır (Ognev, 1931; Kumerlove, 1967; Kock, 1983; Kasparek, 1985; Harrison \& Bates, 1991; Özkurt et al., 1999; Özkurt, Sözen, Yiğit, Çolak, \& Verimli, 2000; Tez, Gündüz, \& Kefelioğlu, 2001; Arslan \& Zima, 2013; İbis \& Tez, 2014). Araştırmacılar tarafından türün diploid kromozom sayısı $2 n=38$ olarak tespit edilirken kromozomal kol sayılarında farklılıklar görülmüştür. Özkurt et al., (1999) NF ve NFa değerlerini sirasıyla 72 ve 68 olarak verirken Arslan ve Zima (2013) yapmış oldukları çalışmada 74 ve 70 karyotip değerlerini vermişlerdir. Ayrica, Harrison ve Bates (1991) Türkiye' deki benekli kokarcaların V. p. alpheraky alttürüne ait olduğunu belirtirken, Kumerloeve (1967), ülkenin batısında $V$. p. syriaca alttürünün, doğusunda ise $V . p$. alpheraky alttürünün yayılış gösterdiğini ifade etmiştir.

Ülkemizde lokal ya da bölgesel düzeyde birçok alandan alacasansar kaydı verilmiştir. Ancak yaban hayvanlarına ait türlerin yayılışını daha iyi açıklamak için lokalite araştırmaları da önem arz etmektedir. Bu çalışma ile özellikle insan aktiviteleri sonucu yaban hayvanlarının yaşam alanlarının daralması, besin kaynaklarının azalması gibi etkenler ile popülasyon yoğunluğu düşen $V$. peregusna türünün ülkemizdeki dağılış sınırları ile ekolojik özelliklerine katkı sunulması amaçlanmıştır.

2016-2018 tarihleri arasinda memeli yaban hayvanlarına yönelik doğrudan ve dolaylı gözlem yöntemleri kullanılarak arazi çalışmaları 
gerçekleştirilmiştir. Çalışmalarımız memeli türlerinin aktif oldukları sabah gündoğumu ile akşam günbatımı saatlerinde gerçekleştirilmiştir. Örnekleri görüntülemek için DSLR fotoğraf makinaları kullanılırken, tespit edildikleri lokalitelere ait koordinatlar GPS ile alınmıştır. Çalışmalar esnasında Batman Doğa Koruma Milli Parklar İl Müdürlüğüne (DKMP) vatandaşlar tarafından canlı olarak getirilen alacasansara ait dış morfolojik ölçümler ve görüntüler alındıktan sonra yine DKMP yetkilileri ve veteriner eşliğinde sağlık kontrolleri yapılmış ve doğal habitatlarında serbest bırakılmıştır. Bu çalışma ve daha önce ülkemizden verilen alacasansar kayıtları şekil 1'de haritada gösterilmiştir.

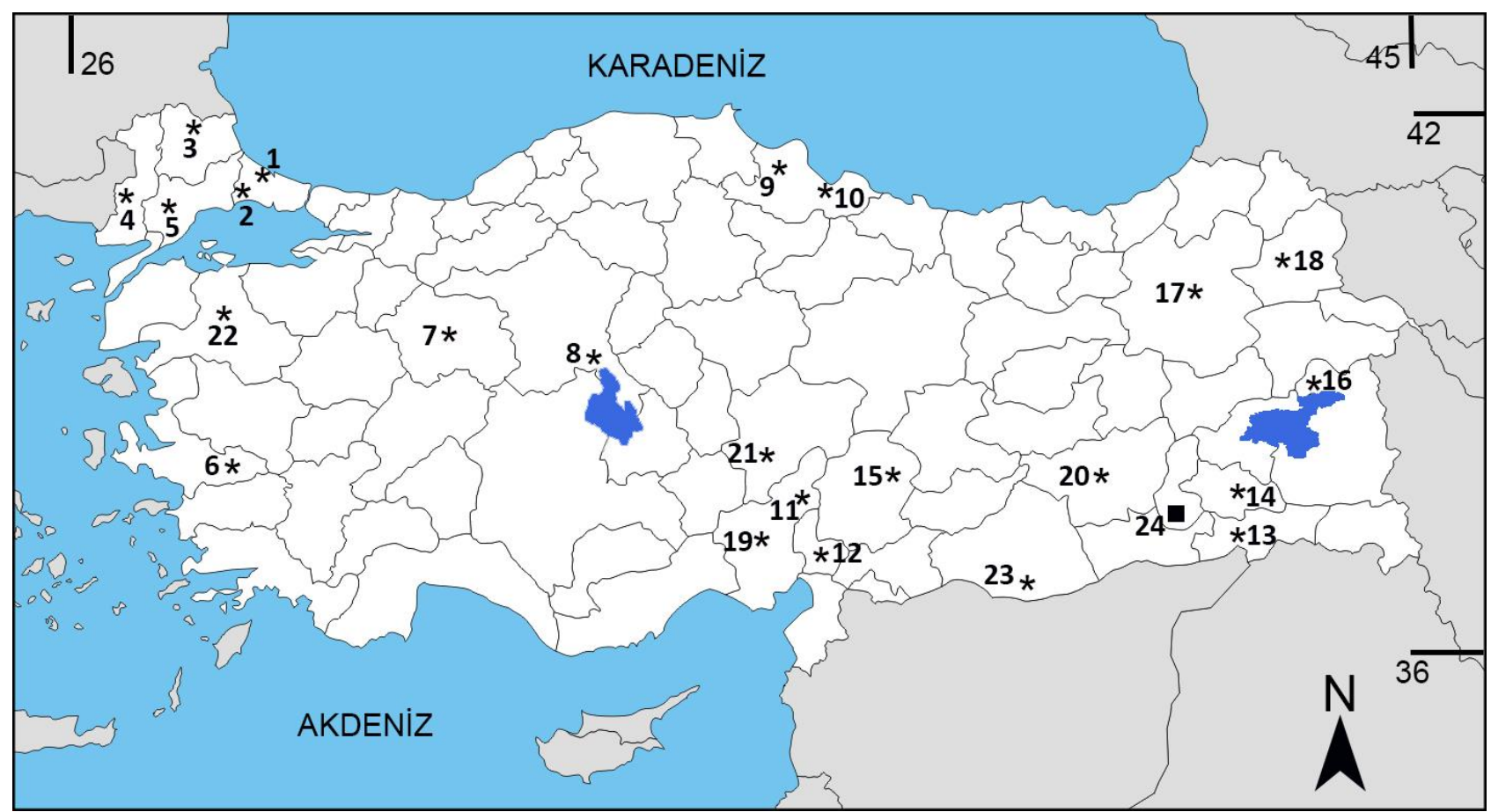

Şekil 1: Benekli kokarca'nın ülkemizden daha once verilen kayıtları ile bu çalışmada tespit edilen lokaliteler (1.İstanbul, 2.Çatalca, 3.Istıranca Dağları, 4.Meriç Nehri, 5.Tekirdă̆, 6.İzmir, 7.Eskişehir, 8.Tuz Gölü, 9.Vezirköprü, 10.Samsun, 11.Kadirli, 12.Osmaniye, 13.Cizre, 14.Siirt, 15.Kahramanmaras,, 16.Van Gölü, 17.Erzurum ve 18.Göle-Kars (Kumerlove, 1967); 19.Adana, 20.Diyarbakır, 21.Yeşilhisar-Kayseri (Kasparek, 1985); 22.Gönen (Özkurt et al., 1999); 23.Ceylanpınar (Özkurt et al., 2000), 24. Batman (Bu çalışma)

Çalışma alanında tespit edilen alacasansar küçük bir kafa ve buruna sahipken kuyrukları uzun ve gür kıllarla kaplıdır. Dorsal kürk rengi beyaz üzerine sarı-kahverengi mermer deseni gibi alacalı, karın kısmı ve ayakları siyahımsı kahverengi kıllarla örtülüdür. Gözleri ve yanakları boyunca şerit şeklinde geniş siyah-kahverengi kıllar bulunan alacasansarın beyaz renkli yüzü maskeli gibi görünmektedir (Şekil 2A). Yuvarlak yapıda olan kulaklarının proksimal kisminda siyah kıllar distal kısmında ise beyaz kıllar bulunmaktadır. Kuyruğun proksimal kısmı sarımsı kahverengi, orta kısmı beyaz ve

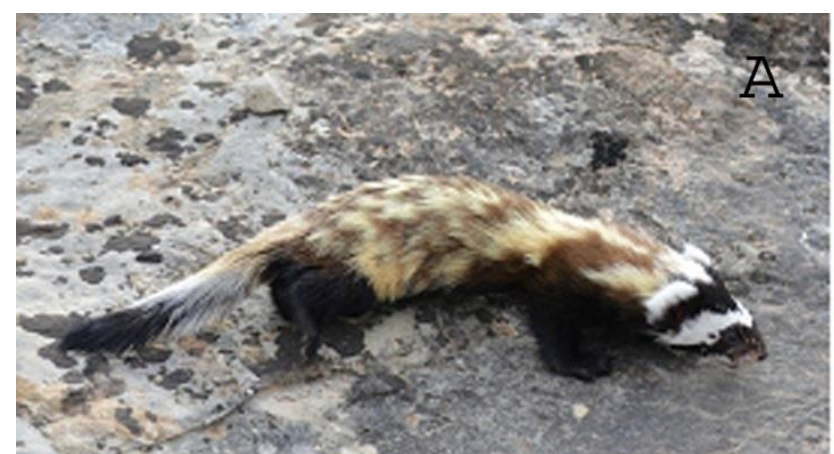

distal kısmı ise siyah renklidir. Benekli kokarcanın vücudu uzun olup, ayakları kısa olduğundan vücut yere yakındır ayrıca kuyruklarının uç kısmında kuyruğun yaklaşık 1 /3'i uzunluğunda geniş siyah kıllarla kaplı bir bant bulunmaktadır (Şekil 2B). Çalışma alanında tespit edilen 443 gr ağırlığındaki dişi bireyin tüm boy uzunluğu 342, kuyruk uzunluğu 158, kuyruk ucundaki siyah bant uzunluğu 56, ardayak uzunluğu 44 ve kulak uzunluğu 29 mm olarak ölçülmüştür. Batman örneğindeki bu ölçümler Gorsuch ve Larivière (2005)'nin çalışmalarındaki Lübnan örnekleri ile uyum göstermektedir.

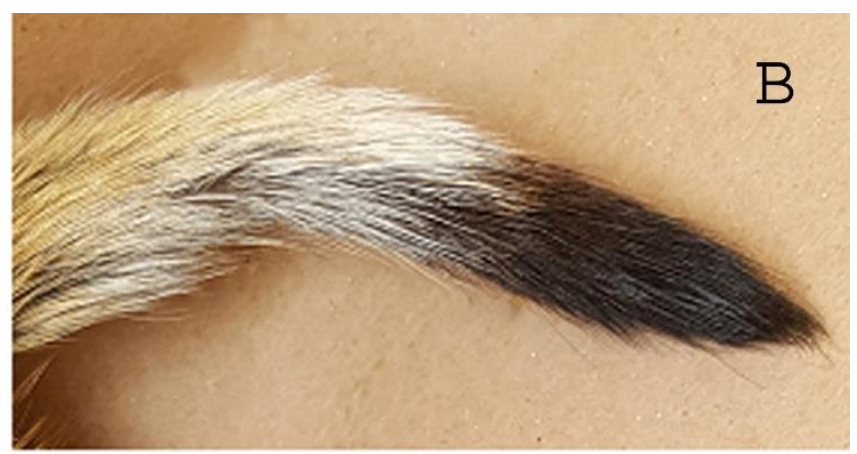

Şekil 2: Batman yöresinde tespit edilen Alacasansar'ın (A) genel görünüşü ve (B) kuyruk ucundaki siyah bant.

Özkurt et al., (1999), yapmış oldukları çalışmada kuyruk uçlarında bulunan siyah bant özelliği bakımından Gönen-Balıkesir örneklerinin $V$. p. syriaca ile benzer olduğunu belirtmişlerdir. Ancak, Şanlıurfa-Ceylanpınar örneklerinde kuyruk ucundaki siyah bandın Balıkesir örneklerine göre daha ince olması bu farklılığın alttüre mi yoksa eşeye mi bağlı bir varyasyon olduğu konusunda araştırıcıları kararsız bırakmıştır (Özkurt et al., 2000). Kuyruk ucundaki siyah bant bakımından örneklerimiz Balıkesir-Gönen örnekleri (Özkurt et al., 1999) ile benzerlik 
gösterirken, Şanlıurfa-Ceylanpınar (Özkurt et al., 2000) ve kuyruklarının uç kısmında siyah bant bulunmayan Ürdün (Rifai et al., 1999) alacasansar örnekleri ile farklılık göstermektedir.

İnsanoğlunun enerji ve besin kaynaklarını bilinçsizce kullanması sonucunda birçok yaban hayvanı gibi sansarların da doğal yaşam alanları ortadan kalkmakta (Lefeuvre et al., 2003; Desrocher et al., 2008; Chen et al., 2016) ve sayıları azalma eğiliminde olup IUCN kırmızı listesine göre duyarlı (VU) kategorisinde yer almaktadır (IUCN, 2018). Benekli kokarcaların habitatına yakın tarım alanlarının varlığı ve bu tarım alanlarında kullanılan tarımsal ilaçlar bu türün yaşamını tehdit eden etkenlerdir. Ayrıca birkaç köpek eşliğinde küçükbaş hayvanların geniş bir alanda otlatılması türün yayılış alanlarını sınırlayan ve türü strese sokan nedenlerdendir. $V$. peregusna'nın Türkiye' deki alttür durumu henüz netlik kazanmamıştır. Alacasansarın ülkemizdeki alttür probleminin netlik kazanması ve alttür dağılış sınırlarının belirlenmesi için daha fazla örnekleri kapsayan özellikle moleküler çalışmaların yapılması gerekmektedir.

Bu çalışma Tarım ve Orman Bakanlığı, Doğa Koruma ve Milli Parklar Genel Müdürlüğü tarafından yürütülen "Batman İlinin Karasal Biyolojik Çeşitlilik ve İçsu Ekosistemleri Biyolojik Çeşitlilik ve Envanter İzleme Projesi" kapsamında gerçekleştirilmiştir.

\section{References}

Albayrak, İ., Pamukoğlu, N., \& Aşan, N. (1997). Bibliography of Turkish Carnivores (Mammalia: Carnivora). Faculty of Science University of Ankara, Series C, 15, 1-20.

Arslan, A., \& Zima, J. (2013). Distribution of C-heterochromatin and Nucleolar Organizer Regions in the Karyotype of Marbled Polecat, Vormela peregusna (Carnivora: Mustelidae). Acta Zoologica Bulgarica, 65(4), 557- 560 .

Ben-David, M. (1991). Feeding Habits and Predatory Behaviour in the Marbled Polecat (Vormela peregusna syriaca): I. Kiling Methods in Relation to Prey Size and Prey Behaviour. Behaviour, (118), 127-143.

Chen, J., Shi, H., Sivakumar, B., \& Peart, M.R. (2016). Population, water, food, energy and dams. Renewable and Sustainable Energy Reviews, 56(C), $18-28$.

Corbet, G.B. (1978). The mammals of the palaearctic region. A taxonomic review. British Museum (Natural History) and Cornell University Press, London and Ithaca (NY), England, pp. 1-314.

Danford, C.G., \& Alston, E. R. (1877). On the Mammals of Asia Minor. Proceedings of the Zoological Society of London, 270-282.

Desrocher, D.W., Keagy, J.C., \& Cristol D.A. (2008). Created versus natural wetlands: Avian communitiesin Virginia salt marshes. Ecoscience, 15 (1), 36-43.

Eken, G., Bozdoğan, M., İsfendiyaroğlu S., Kılıç D. T., \& Lise Y. (editörler) (2006). Türkiye'nin Önemli Doğa Alanları. Doğa Derneği, Ankara, Türkiye, $639 \mathrm{pp}$.

Wanda, A., \& Gorsuch, S.L. (2005). Vormela peregusna. Mammalian Species, $779,1-5$

Harrison, D.L., \& Bates P.J.J. (1991). The Mammals of Arabia. Second Edition. Harrison Zoology Museum Publications, Sevenoaks, Kent, 354 pp.

İbiş, O., Aksöyek, E., Özcan, S., \& Tez, C. (2015b). A preliminary phylogenetic analysis of golden jackals (Canis aureus) (Canidae. Carnivora: Mammalia) from Turkey based mitochondrial D-loop sequences, Vertebrate Zoology, 65(3), 391-397.

İbiş, O., Tez, C., Özcan, S., Yorulmaz, T., Kaya, A., \& Mohammad, M., (2015a). Insights into the Turkish and Iranian Badgers (the Genus Meles) based on the Mitochondrial Cytochrome b Gene Sequences, Vertebrate Zoology, 65(3), 399-407.

İbiş, O., \& Tez, C. (2014). Phylogenetic Status and Genetic Diversity of the Turkish Marbled Polecat, Vormela peregusna, (Mustelidae: Carnivora: Mammalia), Iinferred from the Mitochondrial Cytochrome b Gene. Vertebrate Zoology, 64(2), 285-294.
IUCN, (2018). https://www.iucnredlist.org/species/29680/9525782

Kasparek, M. (1985). Die Sultanssümpfe. Naturgeschichte eines Vogelparadieses in Anatolien, Heidelberg, 154 pp.

Kock, D. (1983). Identifizierung der Palästina-Genetten von J. Ahoroni als Vormela peregusna (Güldenstaedt, 1770). Zeitschrift für Säugetierkunde, 48, 381-383.

Kumerloeve, H. (1967). Zur Verbreitung kelinasiatischer Raub-und. Hugtiere sowie einiger Grobnager. Säugetierkundliche Mitteilungen, 4, 337-409.

Lefeuvre, J.C., Laffaille, P., Feunteun, E., Bouchard, V., \& Radureu, A. (2003). Biodiversity in salt marshes: from patrimonial value to ecosystem functioning. The case study of the Mont-Saint-Michel Bay. Comptes Rendus Biologies, 326: 125-131.

Novikov, G.A. (1962). Carnivorous Mammals of the USSR, Fauna of the USSR No 62. Zoological Institude of the Academy of Sciences of the USSR, Israeli Program for Scientific Translation, Jerusalem, Israel, 284 pp.

Ognev, S.I. (1931). Mammals of Eastern Europe and Northern Asia, Vol. II, Carnivora (Fissipedia). Moskova-Leningrad (Translated from Russian, Israel Program for Scientific Translations. Jerusalem 1962).

Özkurt, Ş., Sözen, M., Yiğit, N., \& Çolak, E. (1999). A Study on Vormela peregusna Güldenstaedt, 1770 (Mammalia: Carnivora) in Turkey. Turkish Journal of Zoology, 23, 141-144.

Özkurt, S., Sözen, M., Yiğit, N., Çolak, E. \& Verimli, R. (2000). On Colouration and Karyology of the Marbled Polecat, Vormela peregusna, in Turkey. Zoology in the Middle East, 21, 13-18.

Peshev, D.T., \& Al-Hossein, K. (1989). Karyology and Biochemical Characteristics of the Polecat (Vormela peregusna syriaca Pockock) (Carnivora: Mustelidae) from Syria. Acta Zoologica Bulgarica, 38: 54-57.

Pocock, R.I. (1936). The Polecats of the Genera Putorius and Vormela in the British Museum. Proceedings of the Zoological Society of London, 1936(2), 691-723.

Rıfai, L.B., Al-Shafee, D.M., Al-Melhim, W.N., \& Amr, Z.S. (1999). Status of the Marbled Polecat, Vormela peregusna (Güldenstaedt, 1770), in Jordan. Zoology in the Middle East, 17, 5-8.

Tez, C., Gündüz, İ., \& Kefelioğlu, H. (2001). Contributions to Distribution, Reproduction Biology and Ecology of Vormela peregusna (Güldenstaedt, 1770) (Mammalia: Carnivora) in Turkey. Pakistan Journal of Biological Sciences, 4(1), 74- 76.

Ulutürk, S., \& Yürümez, G. (2017). New records of Lutra lutra Linnaeus, 1758 from Turkey. Commagene Journal of Biology, 1 (1), 21-24.

Wilson, D.E., \& Reeder, D.M. (2005). Mammal Species of the World. A Taxonomic and Geographic Reference. 3rd Ed. Johns Hopkins University Press, Baltimore, Maryland, $2142 \mathrm{pp}$.

Yiğit, N., Çolak, E., Sözen, M. \& Karataş, A. (2006). Rodents of Türkiye: Türkiye Kemiricileri. Editor: Demirsoy, A., Ankara, Türkiye, Meteksan Yayınevi, 154 pp.

Yürümez, G., \& Ulutürk, S. (2016). Hint Oklu Kirpisi Hystrix indica (Kerr, 1792)'nın (Mammalia: Rodentia) Batman Yöresinde Dağılışı. Batman Üniversitesi Yaşam Bilimleri Dergisi, 6(1), 181-186. 